\title{
Cefazedone Sodium
}

National Cancer Institute

\section{Source}

National Cancer Institute. Cefazedone Sodium. NCI Thesaurus. Code C98216.

The sodium salt form of cefazedone, a semi-synthetic first-generation, oral cephalosporin with antibacterial activity. 